\title{
Motivation as a Predictor of Dental Students' Affective and Behavioral Outcomes: Does the Quality of Motivation Matter?
}

\begin{abstract}
Cesar A. Orsini, Vivian I. Binnie, Oscar M. Jerez
Abstract: Since the motivation to study and engage in academic activities plays a key role in students' learning experience and well-being, gaining a better understanding of dental students' motivations can help educators implement interventions to support students' optimal motivations. The aim of this study, grounded in self-determination theory, was to determine the predictive role of different types of motivation (autonomous motivation, controlled motivation, and amotivation) in the affective and behavioral outcomes of dental students. Amotivation is the absence of drive to pursue an activity due to a failure to establish relationships between activity and behavior; controlled motivation involves behaving under external pressure or demands; and autonomous motivation is an internalized behavior with a full sense of volition, interest, choice, and self-determination. A cross-sectional correlational study was conducted in 2016, in which 924 students ( $90.2 \%$ response rate) from years one to six agreed to participate, granting permission to access their current GPAs and completing four self-reported questionnaires on academic motivation, study strategies, vitality, and self-esteem. The results showed that self-determined motivation (i.e., autonomous over controlled motivation) was positively associated with vitality, self-esteem, and deep study strategies and negatively associated with surface study strategies. The contrary results were found for amotivation. In the motivational model, deep study strategies showed a positive association with students' academic performance. Contrary results were found for surface study strategies. This study extends understanding of the differentiation of motivation based on its quality types and suggests that being motivated does not necessarily lead to positive educational outcomes. Autonomous motivation, in contrast to controlled motivation and amotivation, should be supported to benefit students with regard to their approaches to learning and well-being since it can promote students' vitality, self-esteem, deep over surface study strategies, and enhanced academic performance.
\end{abstract}

Cesar A. Orsini, DDS, MEd, FHEA, DHPE, is Assistant Professor, Faculty Development Office, Faculty of Dentistry, Universidad de los Andes, Chile; Vivian I. Binnie, BDS, MPH, SFHEA, PhD, is Senior Clinical University Teacher, School of Medicine, Dentistry, and Nursing, University of Glasgow, U.K.; and Oscar M. Jerez, PhD, is Director of Teaching and Learning Center, Faculty of Economics and Business, Universidad de Chile, Chile. Direct correspondence to Dr. Cesar A. Orsini, Facultad de Odontología, Universidad de los Andes, Monseñor Álvaro de Portillo 12455, Las Condes, Santiago, Chile 7620001; +569956361629; corsini@uandes.cl.

Keywords: dental education, dental students, motivation, academic motivation, self-determination theory, self-esteem, study strategies

Submitted for publication 9/5/18; accepted 11/8/18; first published online 3/11/19 doi: 10.21815/JDE.019.065

$\mathrm{T}$ The motivation to study and to engage in academic activities plays a key role in students' learning experience, well-being, and professional development. ${ }^{1,2}$ This role is of particular relevance for dental education, which has been characterized through the years as a highly demanding and controlling program in which students, in addition to the heavy workload and study hours, are responsible for the direct treatment of patients during their clinical training. ${ }^{3,4}$ Limited research, however, has been conducted in dental education concerning motivation and its consequences for students' learning experiences.
Among several theories of motivation, selfdetermination theory (SDT) investigates the roles of self-determined (intrinsic reasons to engage) and controlled behaviors (extrinsic reasons to engage) in various environments, emphasizing the importance of studying motivation as a multidimensional construct based on different quality types and not as a unitary construct that only varies in amount (i.e., having more or less motivation). ${ }^{5}$ Figure 1 illustrates the types of motivation postulated by SDT, ranging from the least to the most self-determined types. Amotivation, at the left end of the continuum, is the absence of intent or drive to pursue an activity due to one's failure to 


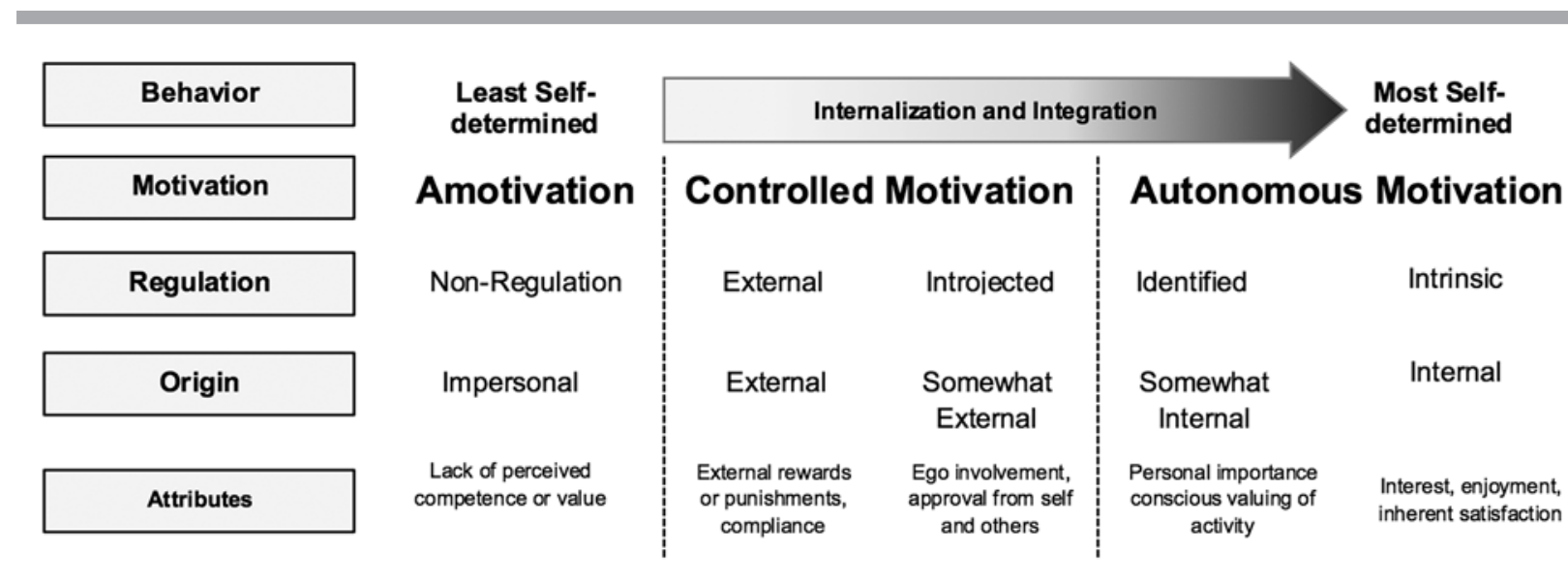

Figure 1. The self-determination continuum, depicting types of behavior, motivation, regulation, origin, and attributes

Source: Adapted with permission from Ryan RM, Deci EL. Self-determination theory and the facilitation of intrinsic motivation, social development, and well-being. Am Psychol 2000;55(1):68-78.

establish contingencies between activity and behavior (e.g., a dental student not wanting to study or not seeing the point in studying for a microbiology exam because he or she expects to fail anyway). ${ }^{6}$ Amotivation is characterized by an impersonal origin and has been associated with negative educational outcomes, such as negative emotions, ${ }^{7,8}$ psychological maladjustment to university education, ${ }^{9}$ and high stress levels. ${ }^{10}$

At the middle and right of the continuum are controlled motivation and autonomous motivation, both of which reflect intention and motivation to act; however, their origins, attributes, and outcomes differ. ${ }^{6}$ Controlled motivation involves behaving under external pressure and demands for specific outcomes. It is subdivided into external and introjected regulation. In external regulation, students' motivation is to obtain rewards or to avoid punishment (e.g., a dental student adjusting the occlusion of a recently performed restoration exclusively to obtain a better mark and to avoid negative feedback from a tutor). In introjected regulation, students' behavior and motivation serve to avoid internal conflict, such as meeting externally imposed standards, to assuage one's ego, or to avoid feeling guilty (e.g., a dental student exerting additional effort to study for an anatomy exam because a poor performance will lead to guilty feelings and less respect from peers). Controlled motivation has also been associated with negative educational outcomes, such as anxiety, ${ }^{7}$ surface motives, and a reproductive orientation toward learning. ${ }^{8,11}$

At the far right of the continuum is autonomous motivation, which represents an internalized behavior with a full sense of volition, interest, choice, and selfdetermination. ${ }^{6}$ It has been divided into identified and intrinsic regulation. In identified regulation, behavior may not be motivated by pleasure and interest, but it becomes internalized as valued and important and is practiced out of choice (e.g., a dental student who does not particularly enjoy oral surgery engages in a suturing workshop and values the activity after a tutor gives a clear rationale for why it is important for professional development). In intrinsic regulation, students engage in activities out of pleasure, interest, and satisfaction (e.g., a dental student conducting a literature review for a public health research project because of genuine interest in the topic and desire for deeper knowledge).

Reports from other educational settings have suggested an association between autonomous motivation and positive behavioral and affective outcomes. ${ }^{8,11,12}$ Previous studies have found that autonomous motivation contributed to better learning strategies (a deep or meaning-oriented strategy over a surface or reproductive-oriented strategy) and enhanced academic performance ${ }^{10,13}$ and promoted students' self-esteem and vitality. ${ }^{5,14}$ Self-esteem represents an individual's set of thoughts and feelings about one's own worth and importance, showing a global positive or negative attitude toward oneself, while the concept of vitality refers to the state of feeling alive and alert and having energy available to oneself. ${ }^{5}$ Despite its relevance, the influence that motivation has on these outcomes has not yet been explored in dental education in order to determine the role and significance that understanding types of 
motivation might offer to the teaching and learning of dentistry.

Therefore, the aim of this study, grounded in self-determination theory, was to determine the predictive role of different quality types of motivation (autonomous motivation, controlled motivation, and amotivation) in the affective and behavioral outcomes of dental students. We sought to better understand dental students' motivations by testing the predictive roles of autonomous motivation, controlled motivation, and amotivation in the affective outcomes of self-esteem and vitality and the behavioral outcomes of study strategies and academic performance, all of which have been found to be key variables for higher education students. ${ }^{2,15}$ We tested the following hypotheses: 1) that self-determined motivation would positively predict self-esteem and vitality, while amotivation would result in the opposite; 2) that self-determined motivation would positively and negatively predict deep and surface study strategies, respectively, while amotivation would result in the opposite; and 3) that, in the motivational model, deep study strategies would positively predict students' academic performance, while the contrary would result in surface study strategies (Figure 2). The findings should make important contributions to dental education regarding both methods and advancement of the understanding of students' motivations, which could justify further interventions to support students' optimal motivations.

\section{Methods}

The Research Ethics Committee of the Faculty of Dentistry of the University San Sebastian in Santiago, Chile, provided ethical approval of the study (Reference Number: 2015-03-08/03). The study was conducted in 2016 at the Faculty of Dentistry of the University San Sebastian in Santiago, Chile. The approach to empirical research was a quantitative correlational cross-sectional survey design, ${ }^{16,17}$ with data gathered through self-reported questionnaires and analyzed through descriptive and inferential methods with special emphasis on the use of structural equation modeling (SEM).

We had access to the total undergraduate dental student population $(\mathrm{n}=1,024)$ and therefore invited all students from years one to six to participate; thus, no sampling strategy was selected. However, an a priori power analysis for multiple regression was calculated for identification of small effects on relationships between the variables. This analysis resulted in a sample size of 647 students, considering an alpha of 0.05 and power of 0.80 using $G^{*}$ Power software, version 3.1.9.2 (Heinrich-Heine-Universität, Düsseldorf, Germany). ${ }^{18}$

Students were asked to voluntarily complete four self-administered questionnaires, after providing written informed consent at the end of a large-group activity. They were informed that we were interested

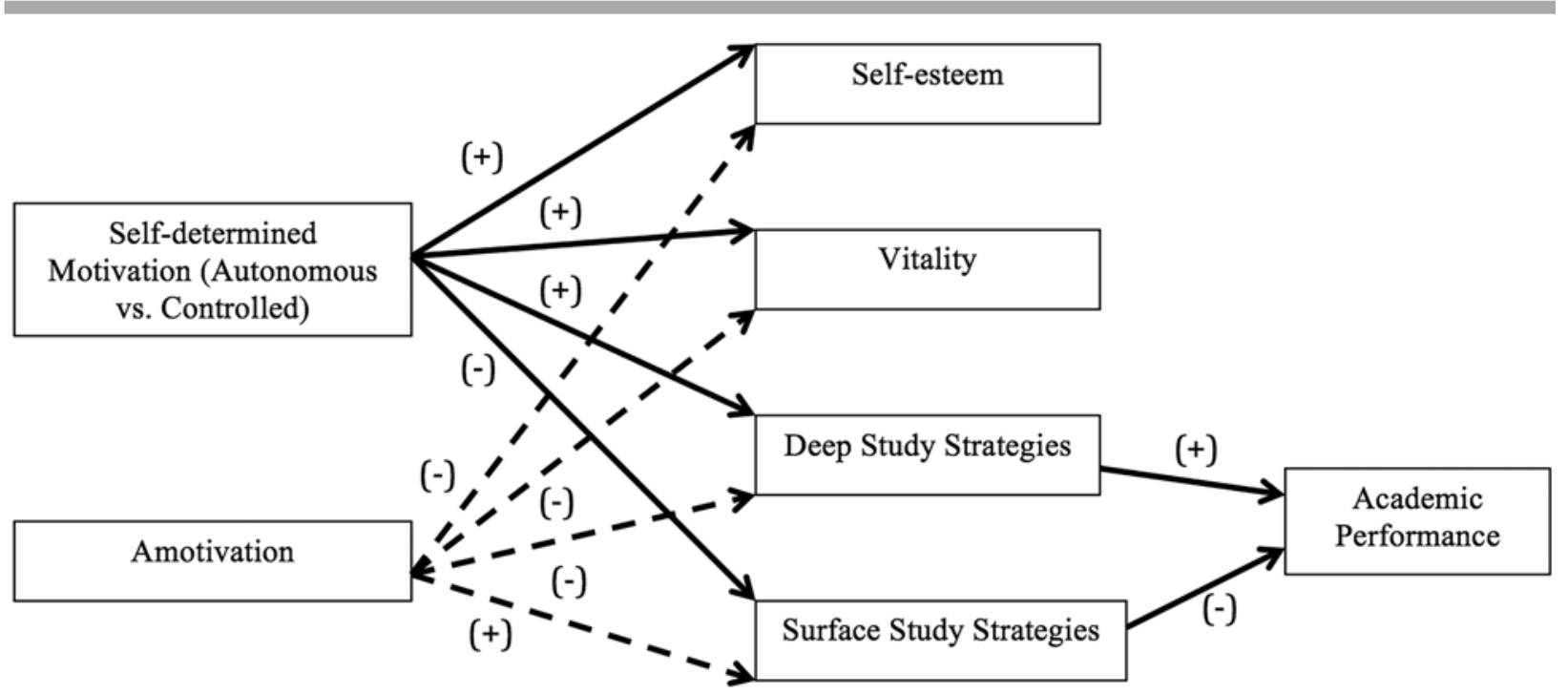

Figure 2. Hypothesized model depicting expected associations between students' motivation and affective and behavioral educational variables 
in better understanding their motivations toward university education and how these motivations affected educational outcomes. Students could withdraw at any time with no consequences or explanations required and with guaranteed confidentiality of the data provided.

\section{Data Collection}

Demographic data were collected regarding age, gender, year of study, and the first seven digits (out of nine) of students' registration numbers to match the surveys with their concurrent academic performance. These partially given numbers acted as codes and did not allow for tracing the students' names.

Academic motivation was assessed using the 28-item Spanish version of the Academic Motivation Scale (AMS), which is divided into subscales of four items each, representing the motivation types postulated by SDT. ${ }^{8}$ Furthermore, the subscales of the AMS that form autonomous and controlled motivation were combined into one score: relative autonomous motivation (RAM). This score provided a general index of students' level of self-determined motivation by estimating the degree of autonomous motivation over controlled motivation. ${ }^{13}$ The score was calculated by combining, assigning weights, and adding intrinsic regulation $(+2)$, identified regulation $(+1)$, introjected regulation (-1), and external regulation (-2). Therefore, a positive RAM suggested an autonomous or self-determined profile, which is considered the good type of motivation, whereas a negative RAM indicated a controlled or a non-selfdetermined profile. ${ }^{6}$

Deep and surface study strategies were assessed using the subscales of deep and surface study strategy of the Spanish version of the Revised Study Process Questionnaire (R-SPQ-2F), which contains ten items per subscale with response options on a five-point Likert scale. ${ }^{19}$ To assess self-esteem, we used the Spanish version of the Rosenberg Self-Esteem Scale (RSES) ${ }_{2}^{20}$ which is a one-dimensional instrument that captures subjects' global perceptions of their own worth by means of ten items with response options on a four-point Likert scale. With regard to vitality, students were asked to complete the Spanish version of the Subjective Vitality Scale, which has six items with response options on a seven-point Likert scale. ${ }^{21}$ The dental school's administrative department provided data on students' academic performance (concurrent GPA).
All of these instruments have shown acceptable reliability and validity in previous studies with similar samples. ${ }^{19-21}$ Also, we adapted all of the measures so that they specifically referred to the dental education context. A high score on a subscale indicated high agreement with the particular variable.

\section{Data Analysis}

Data analysis was performed using PASW Statistic (version 22.00; SPSS Inc., Chicago, IL, USA) and AMOS (version 20.0; SPSS Inc.) software, with the significance level set at $\leq 0.05$. All of the data were screened and checked for the assumptions of the general linear model. Subsequently, the internal consistencies of all of the scales were analyzed by means of Cronbach's alpha scores, and descriptive statistics of all of the measures were calculated. Then, bivariate correlations among all of the constructs were calculated by means of Pearson's correlation coefficient.

Finally, SEM analysis was conducted to test both the model's fit to the data (by means of confirmatory factor analysis) and the model's paths (by interpreting parameter estimates). ${ }^{22,23}$ This step was conducted following Kline's suggestions for SEM analysis through the maximum likelihood method. ${ }^{22}$ We controlled for the effects of gender and year of study, as previous research has suggested their confounding effects on students' motivations. ${ }^{8,13}$ To evaluate model fit and because there are no gold standards in SEM that automatically and objectively lead to a decision of whether or not to retain a model, we tested a series of statistics. We included (with standards for acceptance in parenthesis) the chi-square test $\left(\chi^{2}\right.$, $>0.05$ ), the goodness-of-fit index (GFI, $>0.90$ ), the comparative fit index (CFI, $>0.90$ ), and the root mean square error of approximation (RMSEA, <0.08). To analyze parameter estimates, standardized path scores (associated with unstandardized significance) were interpreted as regression coefficients.

\section{Results}

After data screening, 17 questionnaires were excluded because of missing data; therefore, the final sample consisted of 924 students $(90.2 \%$ response rate). The participants had an average age of 22.8 years $(\mathrm{SD}=3.36)$ and a gender distribution of 583 $(63 \%)$ women and $341(37 \%)$ men, which was far greater than the power analysis calculations. 


\section{Reliability, Descriptive Scores, and Correlations}

Table 1 shows the internal consistency of the scales, means, standard deviations, and correlations for all of the variables. The internal consistency ranged from 0.641 to 0.912 for the Cronbach's alpha values. These results are consistent with scores reported in studies with medical, ${ }^{13}$ dental, ${ }^{8,24}$ and general higher education students, ${ }^{25}$ suggesting that the measures used were reliable in the context of this study.

In terms of reasons for attending university, students reported identified regulation with the highest score and amotivation as the least endorsed regulation type. In summary, students' autonomous motivation for attending university was higher than their controlled motivation, which was confirmed by a positive $\mathrm{RAM}(1.90, \mathrm{SD}=12.28)$, implying an overall self-determined profile. These results are in agreement with previous research conducted in dental, medical, and psychology education ${ }^{8,9,26-29}$ and support the claims that students in health professions education have autonomous motivation profiles. ${ }^{2,30}$

Regarding correlations, autonomous motivation showed strong correlations with the types of regulations that are included in it (intrinsic motivation and identified regulation), which became weaker when correlated with the constructs of controlled motivation (introjected regulation and external regulation). The opposite results were shown for controlled motivation. For amotivation, negative correlations were found with all of the other motivation variables. This finding was not surprising since all of these constructs represent the intention to act (despite coming from internal or external sources), whereas amotivation reflects the lack thereof. These associations provide additional support for the construct validity of the motivational variables.

Concerning associations between motivational variables and behavioral and affective outcomes, students' autonomous motivation was positively associated with deep study strategies, academic performance, vitality, and self-esteem and was negatively associated with surface study strategies. Controlled motivation showed positive associations with surface study strategies and positive but weak correlations with deep study strategies and vitality, showing negative correlations with self-esteem and academic performance. Amotivation, as expected, showed negative associations with all of the behavioral and affective outcome variables with the exception of surface study strategies. These results suggested that, as these dental students' self-determination was internalized and increased in quality, their deep study strategies, academic performance, vitality, and self-esteem also increased, with a decrease in surface study strategy scores.

Table 1. Bivariate correlations, internal consistency, and mean (SD) of all measures

\begin{tabular}{|c|c|c|c|c|c|c|c|c|c|c|c|c|}
\hline & AM & IR & IDR & $\mathrm{CM}$ & INR & EXR & Amot & Vit & SE & DSS & SSS & GPA \\
\hline AM & - & $0.91^{* *}$ & $0.90^{* *}$ & $0.49 * *$ & $0.51^{* *}$ & $0.33^{* *}$ & $-0.44^{* *}$ & $0.25^{* *}$ & $0.16^{* *}$ & $0.38^{* *}$ & $-0.08^{*}$ & $0.07^{*}$ \\
\hline IR & & - & $0.62^{* *}$ & $0.42^{* *}$ & $0.49^{* *}$ & $0.20^{* *}$ & $-0.37 * *$ & $0.29 * *$ & $0.17^{* *}$ & $0.45^{* *}$ & $-0.12^{* *}$ & $0.10^{* *}$ \\
\hline IDR & & & - & $0.47^{* *}$ & $0.42^{* *}$ & $0.40^{* *}$ & $-0.42^{* *}$ & $0.15^{* *}$ & $0.13^{* *}$ & $0.22^{* *}$ & -0.01 & 0.03 \\
\hline $\mathrm{CM}$ & & & & - & $0.89^{* *}$ & $0.84^{* *}$ & $-0.10^{* *}$ & $0.07 *$ & -0.03 & 0.03 & $0.20^{* *}$ & -0.01 \\
\hline INR & & & & & - & $0.50^{* *}$ & $-0.10^{* *}$ & $0.10^{* *}$ & -0.03 & $0.08^{*}$ & $0.14^{* *}$ & -0.01 \\
\hline EXR & & & & & & - & -0.06 & 0.01 & -0.03 & -0.04 & $0.21^{* *}$ & 0.03 \\
\hline Amot & & & & & & & - & - & $-0.31^{* *}$ & $-0.14^{* *}$ & $0.23^{* *}$ & $0.12^{* *}$ \\
\hline Vit & & & & & & & & - & $0.42^{* *}$ & $0.31^{* *}$ & -0.04 & 0.04 \\
\hline SE & & & & & & & & & - & $0.22^{* *}$ & $-0.20 * *$ & $0.11^{* *}$ \\
\hline DSS & & & & & & & & & & - & -0.03 & $0.09^{* *}$ \\
\hline SSS & & & & & & & & & & & - & - \\
\hline GPA & & & & & & & & & & & & - \\
\hline Alpha & 0.905 & 0.897 & 0.687 & 0.827 & 0.826 & 0.724 & 0.831 & 0.912 & 0.772 & 0.650 & 0.641 & - \\
\hline Mean (SD) & $\begin{array}{l}23.23 \\
(3.10)\end{array}$ & $\begin{array}{l}21.91 \\
(3.49)\end{array}$ & $\begin{array}{l}24.66 \\
(3.37)\end{array}$ & $\begin{array}{l}21.87 \\
(4.37)\end{array}$ & $\begin{array}{l}21.14 \\
(5.49)\end{array}$ & $\begin{array}{l}22.73 \\
(4.61)\end{array}$ & $\begin{array}{c}6.71 \\
(4.41)\end{array}$ & $\begin{array}{c}4.85 \\
(1.36)\end{array}$ & $\begin{array}{l}32.52 \\
(4.60)\end{array}$ & $\begin{array}{l}16.41 \\
(3.50)\end{array}$ & $\begin{array}{l}13.31 \\
(3.81)\end{array}$ & $\begin{array}{c}4.72 \\
(0.54)\end{array}$ \\
\hline
\end{tabular}

$\mathrm{AM}=$ Autonomous Motivation, IR=Intrinsic Regulation, IDR=Identified Regulation, $\mathrm{CM}=$ Controlled Motivation, INR=Introjected Regulation, EXR=External Regulation, Amot=Amotivation, Vit=Vitality, SE=Self-Esteem, DSS=Deep Study Strategy, SSS=Surface Study Strategy, GPA=Grade Point Average (Concurrent)

${ }^{*} \mathrm{p}<0.05,{ }^{* *} \mathrm{p}<0.01$ 


\section{Structural Equation Modeling}

The results from the fit statistics showed that the model fit the observed data well. The chi-square test was nonsignificant $\left(\chi^{2}=17.587, \mathrm{df}=10, \mathrm{p}<0.062\right)$, and the results from the CFI (0.991), GFI (0.996), and $\operatorname{RMSEA}(0.29,90 \% \mathrm{CI}=0.000,0.050)$ were all above the standard for acceptance. These results suggest an adequate fit of the model; therefore, the parameter estimates were retained.

Figure 3 shows the standardized regression coefficients of the model (along with their unstandardized significance), in which the control variables of gender and year of study were added. Regression weights showed that all of the relationships were significant and in the hypothesized directions. Regarding the influence of self-determined motivation (expressed by the RAM score) over educational outcome variables, the results showed a positive and significant association with the two affective outcomes, over and above the effects of gender and year of study. Thus, a self-determined motivational profile predicted higher vitality and self-esteem, while the contrary results were shown for amotivation. With regard to behavioral outcomes, self-determined motivation significantly predicted positive deep surface and negative surface learning study strategies over and above the effects of gender and year of study. Amotivation showed the opposite results.

With regard to academic performance, the model showed that motivation influenced this construct through the effects of study strategies. A deep learning study strategy was positively and significantly associated with students' academic performance, while a negative and significant association was found for a surface study strategy. Consequently, the model showed that, when the students' motivation was predominantly autonomous over controlled motivation, positive associations were found with regard to students' feelings about their own worth, their psychological wellness, their approaches to learning, and their concurrent GPA. The contrary outcome was found when the students experienced lack of motivation toward their education.

\section{Discussion}

The results indicated support for hypothesis 1 , with self-determined motivation positively predicting the outcomes of self-esteem and vitality and the contrary results for amotivation. According to these

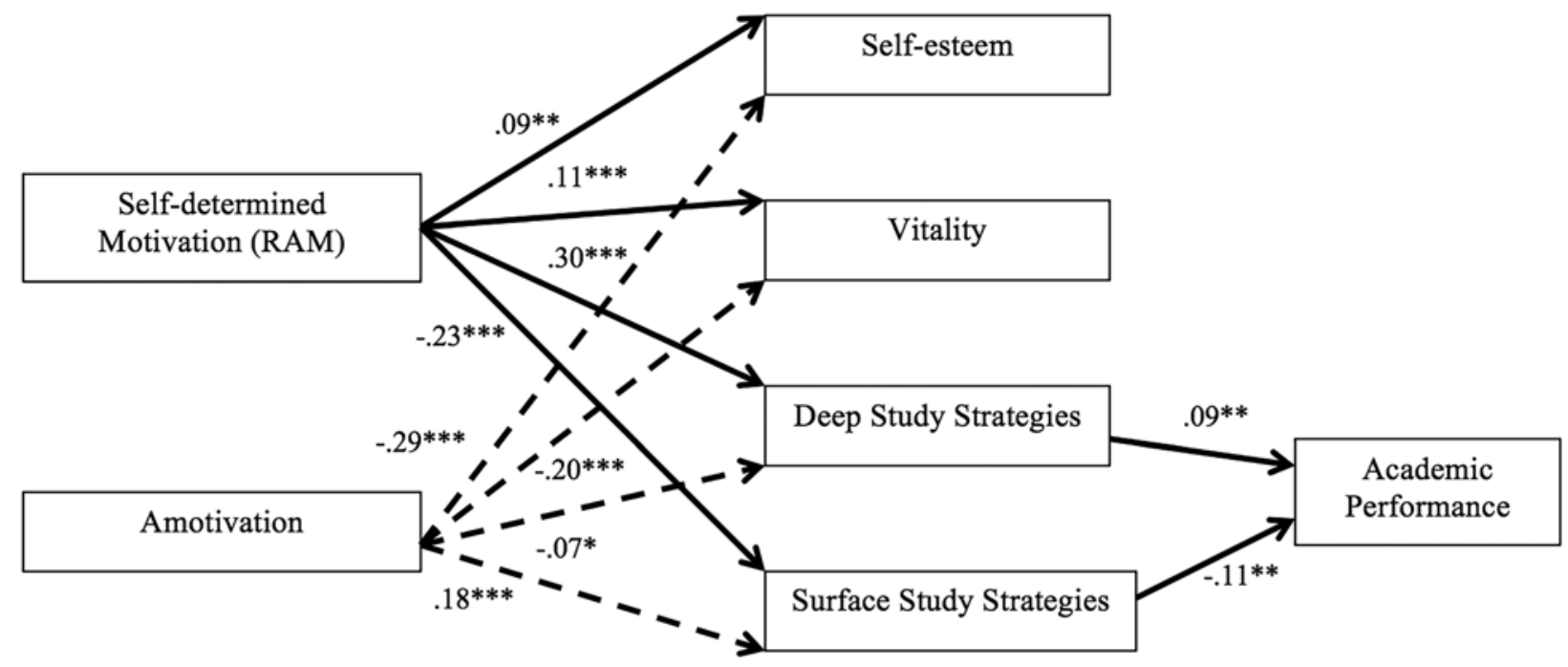

Figure 3. Structural equation model showing standardized regression coefficients among elements of the model for all students

RAM=Relative Autonomous Motivation (Autonomous vs. Controlled)

Note: Residuals, covariances, and regression paths of control variables have been omitted to simplify the model's appearance. Significance in all paths is based on unstandardized regression coefficients, controlling for gender and year of study.

${ }^{*} \mathrm{p}<0.05,{ }^{* *} \mathrm{p}<0.01,{ }^{* * *} \mathrm{p}<0.001$ 
data, we can infer that autonomous motivation was of paramount importance when supporting the students' well-being. This finding supported results from a prior study that found vitality and self-esteem were silent and functional indicators of health. ${ }^{31}$ Moreover, another study found that vitality was an essential indicator of students' emotional engagement in academic activities. ${ }^{32}$ Although there is a lack of studies previously testing the association between motivation and these two constructs in health professions education, our results were consistent with findings in research conducted in other fields of higher education. ${ }^{33-35}$

Our results also supported hypothesis 2 since the students' self-determined motivation positively predicted deep study strategies and negatively predicted surface study strategies, with the opposite results for amotivation. The autonomously motivated dental students seemed to use more effective and deep or meaning-oriented learning strategies and relied less on surface or reproductive-oriented strategies; this pattern tended to reverse when correlated with controlled motivation and amotivation.

These results support previous research in dental education, which linked intrinsic and identified regulation with deep study motives and introjected regulation, external regulation, and amotivation with surface study motives. ${ }^{8}$ They are also in agreement with findings that showed that, as medical students' autonomous motivation increased, so did their deep study strategies. ${ }^{13,28}$ These observations provide support for the claims that optimal types of motivation drive behavior and effort toward success ${ }^{36,37}$ and that autonomously motivated students use more effective learning strategies and show sustained involvement. ${ }^{38}$

Hypothesis 3 was also supported, as the students' deep and surface study strategies were, respectively, positively and negatively associated with academic performance in the motivational model and in correlational analyses. These associations suggest that the quality of motivation had an influence on academic performance through the effects of study strategies. These results seem to be consistent with data obtained from psychology and medical students in different settings, ${ }^{7,10,13}$ although they differed from the findings in a previous study with dental students. ${ }^{8}$ It is important to clarify that the latter study used cumulative instead of concurrent academic performance, which might be a less precise construct due to the dynamic and likely-to-change nature of motivation. Future research should confirm or refute our results in dental education by considering concurrent, rather than cumulative, academic performance.
The results of our study provide acceptable evidence that the quality of motivation was important in determining positive educational outcomes among dental students. These findings have a number of practical implications for educational practice since successes and failures in many elements of professional education can be understood from the SDT perspective. As such, efforts should be made in various aspects of education to support learners' autonomous motivation over controlled motivation and to reduce amotivation.

On the one hand, identifying students' predominant types of motivations as their reason for engaging in academic activities is important since it might lead to different remedial strategies to support students' intentions to act and to improve their educational outcomes. One study found that students' lack of motivation at university appeared to have detrimental effects on their general mental health and posed a higher dropout risk. ${ }^{39}$ Amotivated students are usually labeled as those lacking interest in a given activity or subject. This label might not always be the case, as amotivation can also be the result of continuous failures at a given task or the feeling that the challenges are too difficult and therefore unachievable. ${ }^{5}$ For instance, lack of interest might be overcome by providing a meaningful rationale and by presenting professional context problems; continuous failures might be overcome by additional training opportunities and mentoring, while students who feel that challenges are unachievable could be supported by a vicarious learning experience, watching their peers, near-peers, or tutors perform at the desirable level. . $^{3,0}$

On the other hand, students in whom controlled motivation predominates experience pressure and anxiety; therefore, their learning is likely to be rote, short-lived, and poorly integrated into their longterm values and skills. Consequently, the question that arises is how to facilitate autonomous motivation over controlled motivation and amotivation. A number of determinants have been identified that foster students' autonomous motivations, such as informative and constructive feedback, a qualitative method of selection, and a supportive and safe learning environment. ${ }^{2,15}$ However, what these determinants that facilitate autonomous motivation have in common is support for three learning environment characteristics that have been termed by SDT the three basic psychological needs for the development and maintenance of autonomous motivation. ${ }^{5}$ These needs correspond to the perception of autonomy (making decisions by one's own will), competence 
(feeling capable of performing a determined task), and relatedness (being accepted and valued by important others). Therefore, as the learning environment and teaching methods are provided in a manner that supports these needs, autonomous motivation will be facilitated over controlled motivation and amotivation. Orsini et al. provided a comprehensive view on how dental faculty members can support these needs and promote autonomous motivation in their everyday teaching. ${ }^{3}$ Previous research with dental students has shown, for instance, that the learning environment and the quality of feedback predicted autonomous motivation when students felt support for their need to feel autonomous, competent, and related to important others. ${ }^{24}$

The results of our study have important implications for the internalization processes of students' motivations and for educational outcomes. The process of internalization and how inputs are received are relevant to students' motivations and thus have important consequences for behavioral and affective outcomes. ${ }^{40,41}$ Hence, for dental education, the facilitation of autonomous forms of motivation is expected to contribute to students' becoming better practitioners.

The main limitation of this study is that it was conducted in one dental school, preventing its generalization to other Chilean schools or other dental education contexts. However, based on the detailed presentation and robustness of the methods, we expect other researchers to favorably judge the transferability of our results. Second, there is a limitation concerning bias from self-reported measures; however, considering that the research did not involve any sensitive issues, minor threats to the validity of the results were expected. Finally, longitudinal and experimental research could be explored in further studies to overcome the limitations of cross-sectional designs and to extend the evidence on the relevance of favoring self-determined forms of motivation over controlled motivation and amotivation.

\section{Conclusion}

This study found that a self-determined motivation profile was positively associated with vitality, self-esteem, and deep study strategies and negatively associated with surface study strategies. The contrary results were found for amotivation. Moreover, in the motivational model, deep and surface study strategies showed positive and negative associations, respectively, with students' academic performance. This research extends our knowledge about the differentiation of motivation based on its quality types and suggests that being motivated does not necessarily lead to positive educational outcomes. Autonomous motivation, in contrast to controlled motivation and amotivation, should be supported to benefit students with regard to their approaches to learning and well-being, as it can promote students' vitality, self-esteem, deep over surface study strategies, and enhanced academic performance. This approach should benefit both students and their patients.

\section{Acknowledgments}

The authors thank all the students for participating in this study and the leadership of the dental school for their constant support. This study was supported by the Association for Dental Education in Europe's 40th Anniversary Scholarship Award, General Stream 2015-16.

\section{Disclosure} authors.

No conflicts of interest were reported by the

\section{REFERENCES}

1. Deci EL, Koestner R, Ryan RM. Extrinsic rewards and intrinsic motivation in education: reconsidered once again. Rev Educ Res 2001;71(1):1-27.

2. Orsini C, Binnie VI, Wilson SL. Determinants and outcomes of motivation in health professions education: a systematic review based on self-determination theory. J Educ Eval Health Prof 2016;13(19).

3. Orsini C, Evans P, Binnie V, et al. Encouraging intrinsic motivation in the clinical setting: teachers' perspectives from the self-determination theory. Eur J Dent Educ 2016;20(2):102-11.

4. Williams GC, Saizow RB, Ryan RM. The importance of self-determination theory for medical education. Acad Med 1999;74(9):992-5.

5. Ryan RM, Deci EL. Self-determination theory: basic psychological needs in motivation, development, and wellness. New York: Guilford Publications, 2017.

6. Deci EL, Ryan RM. Self-determination theory: a macrotheory of human motivation, development, and health. Can Psychol 2008;49(3):182-5.

7. Bailey TH, Phillips LJ. The influence of motivation and adaptation on students' subjective well-being, meaning in life, and academic performance. Higher Educ Res Dev 2016;35(2):201-16.

8. Orsini C, Binnie V, Evans $\mathrm{P}$, et al. Psychometric validation of the academic motivation scale in a dental student sample. J Dent Educ 2015;79(8):971-81.

9. Baker SR. Intrinsic, extrinsic, and amotivational orientations: their role in university adjustment, stress, well-being, and subsequent academic performance. Curr Psychol 2004;23(3):189-202. 
10. Park J, Chung S, An H, et al. A structural model of stress, motivation, and academic performance in medical students. Psychiatry Investig 2012;9(2):143-9.

11. Sobral D. What kind of motivation drives medical students' learning quests? Med Educ 2004;38(9):950-7.

12. Kusurkar R, Croiset G, Kruitwagen C, et al. Validity evidence for the measurement of the strength of motivation for medical school. Adv Health Sci Educ Theory Pract 2011;16(2):183-95.

13. Kusurkar R, Ten Cate O, Vos C, et al. How motivation affects academic performance: a structural equation modelling analysis. Adv Health Sci Educ Theory Pract 2013;18(1):57-69.

14. Reeve J, Deci EL, Ryan RM. Self-determination theory applied to educational settings. In: Deci EL, Ryan RM, eds. Handbook of self-determination research. New York: University of Rochester Press, 2002:183-204.

15. Kusurkar R, Ten Cate O, van Asperen M, et al. Motivation as an independent and a dependent variable in medical education: a review of the literature. Med Teach 2011;33(5):242-62.

16. Cleland J. Exploring versus measuring: considering the fundamental differences between qualitative and quantitative research. In: Cleland J, Durning S, eds. Researching medical education. London: John Wiley \& Sons, 2015:1-14.

17. Illing J. Thinking about research: frameworks, ethics, and scholarship. In: Swanwick T, ed. Understanding medical education: evidence, theory, and practice. Oxford, UK: John Wiley \& Sons, 2011:283-300.

18. Erdfelder E, Faul F, Buchner A. GPOWER: a general power analysis program. Behav Res Methods 1996;28(1):1-11.

19. Justicia F, Pichardo MC, Cano F, et al. The revised twofactor study process questionnaire (R-SPQ-2F): exploratory and confirmatory factor analyses at item level. Eur J Psychol Educ 2008;23(3):355-72.

20. Martin-Albo J, Núñez JL, Navarro JG, et al. The Rosenberg self-esteem scale: translation and validation in university students. Span J Psychol 2007;10(2):458.

21. Balaguer I, Castillo I, García-Merita M, et al. Implications of structured extracurricular activities on adolescents' well-being and risk behaviors: motivational mechanisms. Granada: European Federation of Psychologists' Association, 2005.

22. Kline RB. Principles and practice of structural equation modeling: structural equation modeling. New York: Guilford Publications, 2010.

23. Violato C, Hecker KG. How to use structural equation modeling in medical education research: a brief guide. Teach Learn Med 2007;19(4):362-71.

24. Orsini C, Binnie V, Wilson S, et al. Learning climate and feedback as predictors of dental students' self-determined motivation: the mediating role of basic psychological needs satisfaction. Eur J Dent Educ 2018;22(2):e228-36.

25. Nunez JL, Martín-Albo J, Navarro JG, et al. Validation of the academic motivation scale (AMS) in Paraguay. Rev Interam Psicol 2006;40(3):391-8.
26. Williams GC, Deci EL. Internalization of biopsychosocial values by medical students: a test of self-determination theory. J Pers Soc Psychol 1996;70(4):767-79.

27. Stoeber J, Childs JH, Hayward JA, et al. Passion and motivation for studying: predicting academic engagement and burnout in university students. Educ Psychol 2011;31(4):513-28.

28. Kusurkar R, Croiset G, Galindo-Garré F, et al. Motivational profiles of medical students: association with study effort, academic performance, and exhaustion. BMC Med Educ 2013;13(1):87-95.

29. Orsini C, Binnie V, Fuentes F, et al. Implications of motivation differences in preclinical-clinical transition of dental students: a one-year follow-up study. Educ Med 2016;17(4):193-6.

30. Ten Cate O, Kusurkar R, Williams G. How self-determination theory can assist our understanding of the teaching and learning processes in medical education. AMEE guide no. 59. Med Teach 2011;33(12):961-73.

31. Ryan RM, Deci EL. From ego depletion to vitality: theory and findings concerning the facilitation of energy available to the self. Soc Personal Psychol Compass 2008;2(2): 702-17.

32. Skinner E, Furrer C, Marchand G, et al. Engagement and disaffection in the classroom: part of a larger motivational dynamic? J Educ Psychol 2008;100(4):765-81.

33. Nunez JL, Fernández C, León J, et al. The relationship between teacher's autonomy support and students' autonomy and vitality. Teach Teach 2015;21(2):191-202.

34. Ryan RM, Frederick C. On energy, personality, and health: subjective vitality as a dynamic reflection of well-being. J Pers 1997;65(3):529-65.

35. Nix G, Ryan RM, Manly JB, et al. Revitalization through self-regulation: the effects of autonomous and controlled motivation on happiness and vitality. J Exp Soc Psychol 1999;35(3):266-84.

36. Grolnick WS, Ryan RM. Autonomy in children's learning: an experimental and individual difference investigation. J Pers Soc Psychol 1987;52(5):890.

37. Maslow AH. A theory of human motivation. Psychol Rev 1943;50(4):370.

38. Ames C, Archer J. Achievement goals in the classroom: students' learning strategies and motivation processes. J Educ Psychol 1988;80(3):260.

39. James R, Krause K, Jennings C. The first-year experience in Australian universities: findings from 1994 to 2009. Melbourne: Centre for the Study of Higher Education, University of Melbourne, 2010.

40. Niemiec CP, Ryan RM. Autonomy, competence, and relatedness in the classroom: applying self-determination theory to educational practice. Theory Res Educ 2009;7(2):133-44.

41. Ryan RM, Deci EL. Self-determination theory and the facilitation of intrinsic motivation, social development, and well-being. Am Psychol 2000;55(1):68-78. 